Retrospective Evaluation

\title{
Resorption of Massive Lumbar Disc Herniation on MRI Treated with Epidural Steroid Injection: A Retrospective Study of 28 Cases
}

Sung Jun Hong, MD, PhD, Dae Yu Kim, MD, Hyunju Kim, MD, II Seok Kim, MD, Keun Man Shin, MD, PhD, and Sang Soo Kang, MD, PhD

From: Department of Anesthesiologyand Pain Medicine, Kangdong Sacred Heart Hospital, Hallym University College of Medicine, 445, Gil-dong, Gangdong-gu, Seoul 134-701,

Korea

Address Correspondence: Sang Soo Kang, MD, PhD Associate Professor Department of Anesthesiologyand Pain Medicine, Kangdong Sacred Heart Hospital, Hallym University College of Medicine, 445, Gil-dong, Gangdong-gu, Seoul 134-701, Korea

E-mail: kssege@naver.com

Disclaimer: There was no external funding in the preparation of this manuscript. Conflict of interest: Each author certifies that he or she, or a member of his or her immediate

family, has no commercial association (i.e., consultancies, stock ownership, equity interest, patent/licensing arrangements, etc.) that might pose a conflict of interest in connection with the submitted manuscript.

Manuscript received: 07-08-2015 Revised manuscript received: o1-06-2016

Accepted for publication: 02-03-2016

Free full manuscript: www.painphysicianjournal.com
Background: Although herniated disc fragments may resolve spontaneously, the optimal treatment option for massive lumbar disc herniation (LDH) has not been determined.

Objective: To evaluate the extent of reduction in the size of massive LDH on magnetic resonance imaging (MRI) and the pain relief effect of transforaminal epidural steroid injection (TFESI) during the study period.

Study Design: Retrospective evaluation.

Setting: Hospital and ambulatory pain clinic, Korea.

Methods: After Institutional Review Board approval, we conducted a retrospective review of 28 patients who underwent at least 2 MRIs during the period from January 2012 to December 2014. The size of the herniated mass was determined from the ratio of the anterior-posterior diameter of the spinal canal (C-value) to the maximum anterior-posterior diameter of the herniated disc (H-value) on axial MRI (C-H ratio). We also analyzed visual analogue scale (VAS) scores at baseline (T0), 2 weeks after the first and second TFESI (T1, T2), and at the second follow-up MRI (T3).

Results: The mean C-value was $18.3 \pm 2.9 \mathrm{~mm}$. The mean $\mathrm{H}$-value changed from $10.4 \pm 1.9$ $\mathrm{mm}$ to $4.5 \pm 2.7 \mathrm{~mm}$, and the mean $\mathrm{C}-\mathrm{H}$ ratio changed from $58 \pm 1.0 \%$ to $24 \pm 1.4 \%(P<$ $0.001)$. Twenty-four of 28 patients demonstrated a reduction in the size of the herniation, and the mean reduction rate of the $\mathrm{C}-\mathrm{H}$ ratio was $59 \%$. In 4 patients, the $\mathrm{LDH}$ had not resolved on MRI, but the symptoms had diminished to such an extent that surgery was not required. The mean VAS score had significantly decreased at T1 and showed a continued decrease at the time of the last follow-up $(P<0.001)$.

Limitations: This is a retrospective study and only offers data for patients who chose not to undergo surgery. In addition, the timing of repeat MRI was not standardized.

Conclusion: The majority of cases of massive LDH demonstrated resolution at variable points between 3 and 21 months. TFESI could provide effective pain relief for patients with massive $\mathrm{LDH}$ in the interval without severe neurologic deterioration.

IRB approval: Kangdong Sacred Heart Hospital: IRB Number \# 14-1-10

Key words: Lumbar disc herniation, magnetic resonance imaging, migration, regression, resorption, sequestration, transforaminal epidural steroid injection

Pain Physician 2016; 19:381-388 
T he natural history of a lumbar disc herniation $(\mathrm{LDH})$ is not fully understood, but it is well known that herniated disc fragments may resolve spontaneously over time. The presence of disc extrusion has been considered to be an indication for prompt surgical treatment (1). Although the operative indications have been reported as absolute in patients with cauda equina syndrome (CES), severe motor deficits, and intractable pain (2-3), the clear indications for surgical treatment cannot be established from the literature. There is no optimal operative flow chart for massive LDH associated only with pain.

In this study, we retrospectively reviewed the clinical and radiological outcomes of 28 patients with massive LDH with pain as the only symptom who were treated with transforaminal epidural steroid injection (TFESI). Our objective was to evaluate the extent of reduction in the size of the herniation on magnetic resonance imaging (MRI) and the pain relief effect of TFESI.

\section{Methods}

After Institutional Review Board approval, a retrospective search of records was performed. The cases of 28 patients with massive LDH who chose not to have surgery and who were followed with serial MRIs from January 2012 to December 2014 were reviewed.

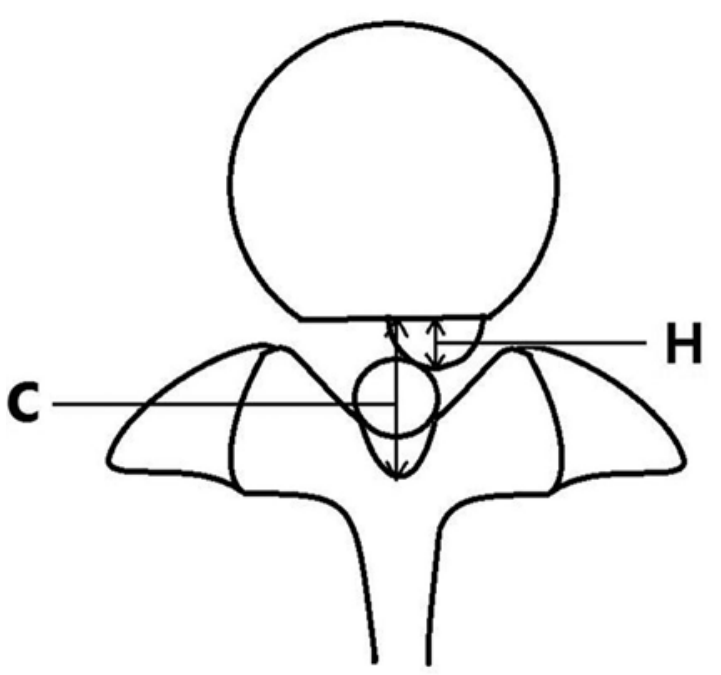

Fig. 1. Method of measuring herniation and spinal canal. C: anterior-posterior diameter of spinal canal, $H$ : maximum anterior-posterior diameter of the herniated disc, and canal-hernia mass ratio: $\mathrm{C} / \mathrm{H}$ ratio $(\%)=C / H \times 100$.
To qualify as a "massive" herniation, at least $50 \%$ or more of the spinal canal had to be occupied by disc material on an axial MRI scan. The size of the herniated mass was determined from the ratio of the anteriorposterior diameter of the spinal canal (C-value) to the maximum anterior-posterior diameter of the herniated disc (H-value) on T2-weighted axial MRI scans. This parameter was designated as the canal-hernia mass ratio ( $\mathrm{C}-\mathrm{H}$ ratio, Fig. 1) $(4,5)$. The nomenclature and classification of lumbar disc pathology relied on the recommendations of the combined task forces of 3 major specialty societies (6). A single radiologist reviewed each of the studies. If there was an obvious reduction in a disc at the follow-up MRI, or symptoms had resolved to such an extent that a follow-up examination was not required, an additional MRI was not obtained.

Pain was scored using a visual analogue scale (VAS) on a $10 \mathrm{~cm}$ horizontal line. VAS scores were measured at baseline (TO), 2 weeks after the first and second TFESI $(T 1, T 2)$, and at the second follow-up MRI scan (T3).

\section{Statistical Analysis}

The paired t-test was used to compare serial changes in the $\mathrm{H}$-value and the $\mathrm{C}-\mathrm{H}$ ratio. The differences in VAS scores between time points were determined with the repeated-measures analysis of variance (ANOVA) with the Tukey-Kramer post-hoc test. Statistical analysis was performed using SPSS software package version 10 (SPSS Inc., Chicago, IL, USA), and all values were expressed as mean \pm standard deviation (SD) and defined as statistically significant in the case of $P<0.05$.

\section{Results}

Twenty-eight consecutive patients underwent serial MRIs during the period under review, and all were included in this study. Sixteen patients were examined twice, and 12 patients were examined more than 2 times. These last scans were performed at a mean time point of 8.8 months ( 2 to 31 ) after the initial scan. The average patient age was 50.2 years (range $26-78$ years) and the distribution of involved disc levels is shown in Table 1. All of these patients received a series of 2 or 3 courses of TFESI at intervals of 2 weeks or more.

Twenty $(71.4 \%)$ cases of LDH were classified as extrusions and the other $8(28.6 \%)$ cases were classified as protrusions. The description and location of the cases of $\mathrm{LDH}$ are shown in Table 2. The initial mean C-value was $18.3 \pm 2.9 \mathrm{~mm}$. The mean $\mathrm{H}$-value changed from $10.4 \pm$ $1.9 \mathrm{~mm}$ to $4.5 \pm 2.7 \mathrm{~mm}(P<0.0001)$ and the mean $\mathrm{C}-\mathrm{H}$ ratio changed from $58 \pm 1.0 \%$ to $24 \pm 1.4 \%(P<0.0001)$. 
Twenty-four of 28 patients demonstrated a reduction in the size of the herniation, and the mean reduction rate of the $\mathrm{C}-\mathrm{H}$ ratio was $59 \%$ (resorption group, $\mathrm{n}=$ 24). There were 4 patients whose disc herniation had not resolved on MRI, but the symptoms had diminished to such an extent that surgery was not required (nonresorption group, $n=4$ ). Seven of 8 patients who had migrated discs showed a reduction in the size of the disc (Table 2).

The resorption ratio by age is as follows: 1 of 1 of patients in their twenties, 3 of 4 patients in their thirties, 11 of 11 patients in their forties, 3 of 6 patients in their fifties, and all of the 6 patients over sixty demonstrated a reduction in the disc size on MRI.

Modic changes of lumbar endplates were observed in $21.4 \%(6 / 28)$ of patients. Two patients with Modic type I changes and 2 patients with type II changes were observed in the resorption group (4/24), and 2 patients with type II changes were observed in the non-resorption group (2/4).

The mean VAS score was significantly decreased at $\mathrm{T} 1$ and showed a continued decrease at the time of last follow-up $(P<0.001$, Fig. 6).

No patient developed CES or severe neurologic deterioration and there were no complications related to TFESI during the study period.

\section{Resorption Group ( $\mathbf{n}=\mathbf{2 4})$}

Twenty-four of $28(85.7 \%)$ patients showed a reduction in the size of the herniation, and the mean reduction rate of the $\mathrm{C}-\mathrm{H}$ ratio was $59 \%$ (30 to $100 \%$ ) on the final MRI. One patient who had the highest C-H ratio $(70 \%)$ showed a $54 \%$ reduction after 3 months (Fig. 2). Four patients demonstrated complete resorption by the time of the second or last MRI (Figs. 3,4). One of
Table 1. Distribution of lumbar disc herniation by gender.

\begin{tabular}{||l|c|c|c||}
\hline \hline & Male (10) & Female (18) & Total \\
\hline L2-3 & & 1 & 1 \\
\hline L3-4 & 1 & 2 & 3 \\
\hline L4-5 & 5 & 6 & 11 \\
\hline L5-S1 & 4 & 9 & 13 \\
\hline All & 10 & 18 & 28 \\
\hline
\end{tabular}

( ) number of patients

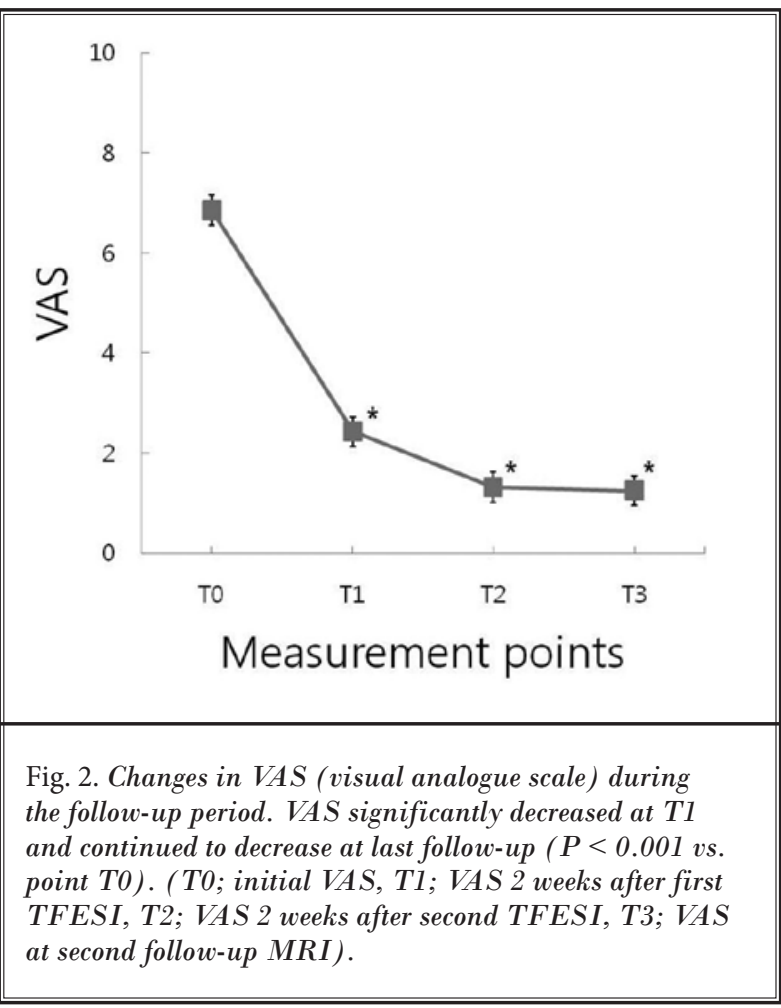

Table 2. Description and location of lumbar disc herniation by level and location.

\begin{tabular}{|c|c|c|c|c|c|}
\hline Classification & Level & $\begin{array}{l}\text { Resorption group } \\
(\mathrm{n}=\mathbf{2 4})\end{array}$ & \# of patients & $\begin{array}{l}\text { Non-resorption group } \\
(\mathrm{n}=4)\end{array}$ & \# of patients \\
\hline $\begin{array}{l}\text { Protrusion } \\
(\mathrm{n}=8)\end{array}$ & $\begin{array}{c}\mathrm{L} 2 / 3 \\
\mathrm{~L} 3 / 4 \\
\mathrm{~L} 4 / 5 \\
\mathrm{~L} 5 / \mathrm{S} 1 \\
\end{array}$ & $\begin{array}{c}\operatorname{Pm}(1) \\
\operatorname{Pm}(1) \\
\mathrm{P}(1), \mathrm{Cm}(1) \\
\mathrm{C}(1), \mathrm{P}(3)\end{array}$ & $\begin{array}{l}(1) \\
(1) \\
(2) \\
(4)\end{array}$ & & $\begin{array}{l}(0) \\
(0) \\
(0) \\
(0)\end{array}$ \\
\hline $\begin{array}{l}\text { Extrusion } \\
(\mathrm{n}=20)\end{array}$ & $\begin{array}{l}\mathrm{L} 2 / 3 \\
\mathrm{~L} 3 / 4 \\
\mathrm{~L} 4 / 5 \\
\mathrm{~L} 5 / \mathrm{S} 1\end{array}$ & $\begin{array}{c}\text { C (1), P (1) } \\
\text { C (2), P (3), Cm (1), Pm (2) } \\
\text { C (1), P (3), L (1), Pm (1) }\end{array}$ & $\begin{array}{l}(0) \\
(2) \\
(8) \\
(6)\end{array}$ & $\begin{array}{c}\text { C (1) } \\
C(1), P(1), C m(1)\end{array}$ & $\begin{array}{l}(0) \\
(0) \\
(1) \\
(3)\end{array}$ \\
\hline \multicolumn{3}{|c|}{ Total number of patients } & (24) & & $(4)$ \\
\hline
\end{tabular}

Abbreviations by location: central (C), paracentral (P), lateral recess (L) location, central location with migration (Cm), and paracentral location with migration $(\mathrm{Pm})$. Paracentral $(\mathrm{P})$ includes both right central or left central location. 

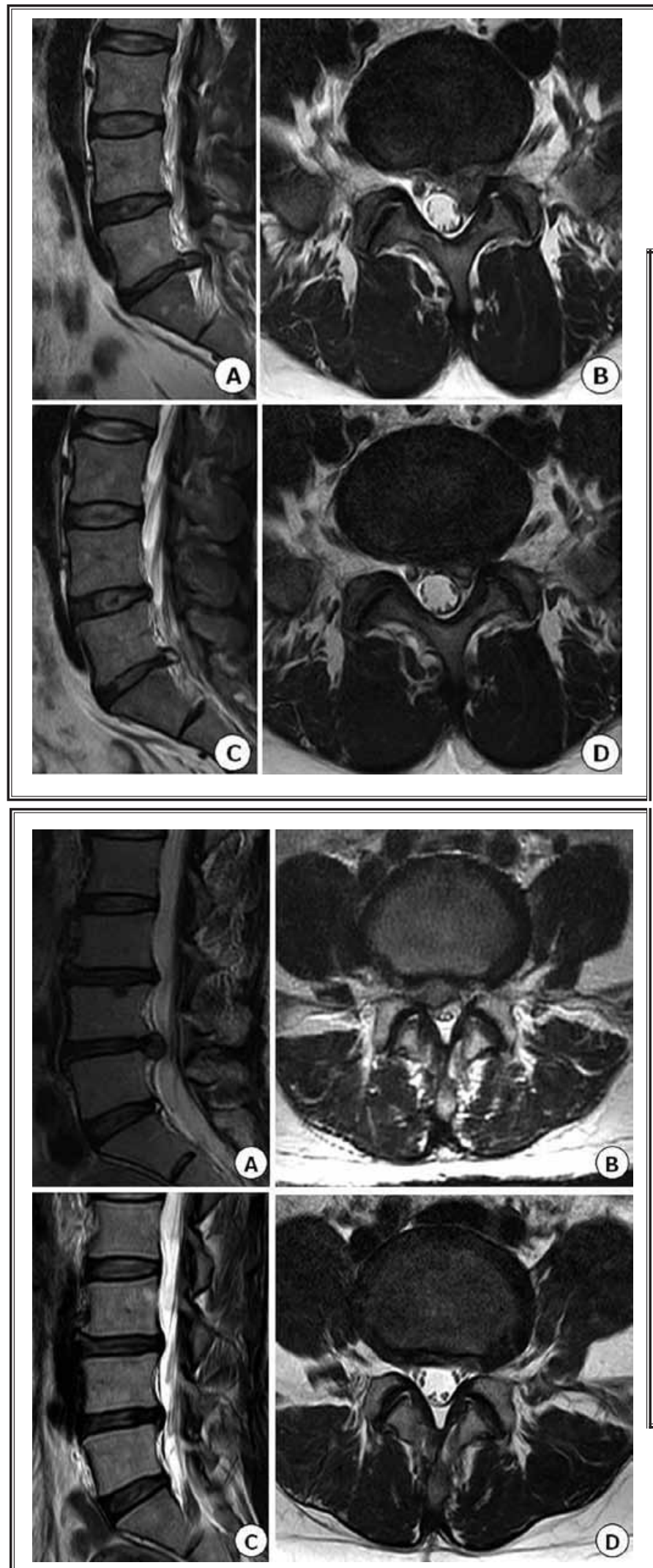

Fig 3. A 38-year-old man. This figure shows a large left central to foraminal disc extrusion compressing and displacing the left S1 nerve root. T2-weighted axial and sagittal views of the L5-S1 disc $(A, B)$. There has been significant resorption of the extruded disc 3 months following the first visit. Although a small left subarticular extrusion persists compressing and displacing the left $S 1$ nerve root, the patient remains free of symptoms.

the patients, who had shown an increase in the herniated disc size during the first 5 months following the initial scan, showed a marked reduction in the herniated disc size 12 months after the initial scan, and complete resorption 24 months after the initial scan (Fig. 5).

\section{Non-resorption Group ( $\mathbf{n}=\mathbf{4})$}

In four (14.3\%) patients whose disc herniation had not resolved on MRI, the symptoms had diminished to such an extent that surgery was not required. The patient who has not shown any change on the MRI for the longest period was still doing well after 31 months, with a VAS score of $1 / 10$.

\section{Discussion}

Spontaneous regression of LDH has been described frequently in the literature. In 1983, Weber (7) reported the same neurologic recovery in groups treated surgically and nonsurgically in his 10-year controlled follow-up computed tomography (CT) study. Guinto et al (8) first reported a case of lumbar disc regression on $C T$ after conservative treatment in 1984. Since then, many studies have been conducted demonstrating that LDH can resolve spontaneously (9-17).

Bozzao et al (12) reported on a series of 8 patients in whom disc herniations occupied more than $50 \%$ of the canal. Six of these patients demonstrated a reduction in the size of the herniated disc by more than $70 \%$ on follow-up axial MRI scans. Cribb et al (17) reported that repeated MRI scanning after a mean of 24 months showed a dramatic resolution in massive LDH in 14 out of 15 patients. Benson et al (18) reported that $83 \%$ of cases of massive LDH demonstrated a complete

Fig. 4. A 44-year-old woman. T2-weighted axial and sagittal views at the L4-5 disc level $(A, B)$, and complete resorption of a right central to subarticular extrusion 4 months after the first visit $(C, D)$. 
and sustained recovery at an average of 23.2 months and an average reduction of $64 \%$ in herniated disc size on serial MRI scans.

In contrast to these previous studies, Seo et al (19) reported that LDH is a dynamic disease that does not always resolve spontaneously in three-dimensional (3D) volumetric measurements from MRI scans. They reported that the volumes in $62 \%(35 / 56)$ of disc levels decreased, while those in $38 \%$ (21/56) of disc levels increased. Volumetric changes in LDH did not significantly correlate with clinical outcomes. They explained that the discrepancy in resorption frequencies between studies may be attributable to patient selection or to measurement errors associated with 2D imaging.

Although many studies have reported on the spontaneous regression of LDH, there has been little published regarding specific treatment options or an analysis of the change in pain during the study period. Therefore, we analyzed the clinical and radiological outcomes in patients with massive LDH who were treated with TFESI, as well as the pain relief effect of TFESI. In our study, we observed that $85.7 \%$ (24/28) of patients experienced a reduction in the size of the herniation. The mean $\mathrm{C}-\mathrm{H}$ ratio reduction was $59 \%$ on the final scan. A previously described phenomenon of preferential resorption of larger herniated disc fragments was also observed in our study. With our demonstration of a statistically significant drop in VAS post-treatment, TFESI has been proven an effective pain relief option for patients with massive LDH during the study period.

Three possible hypotheses exist regarding the process of disc resorption. The first is retraction, the second is dehydration and

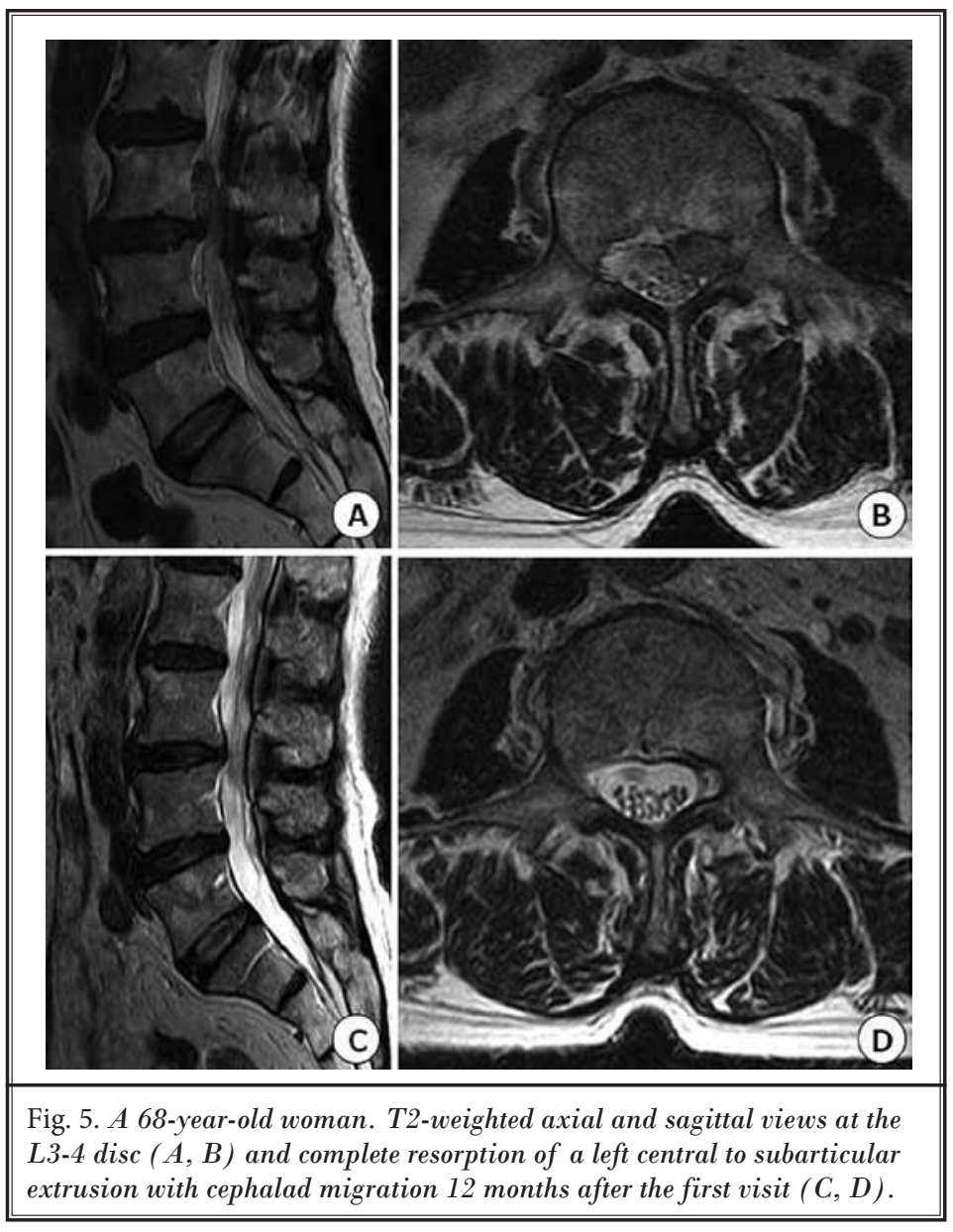

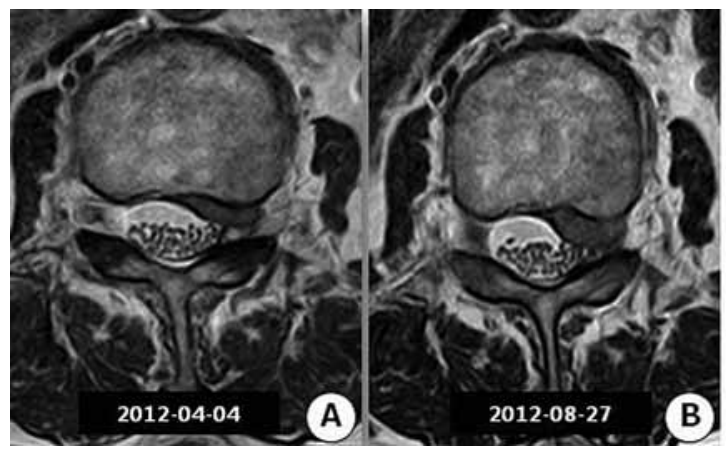
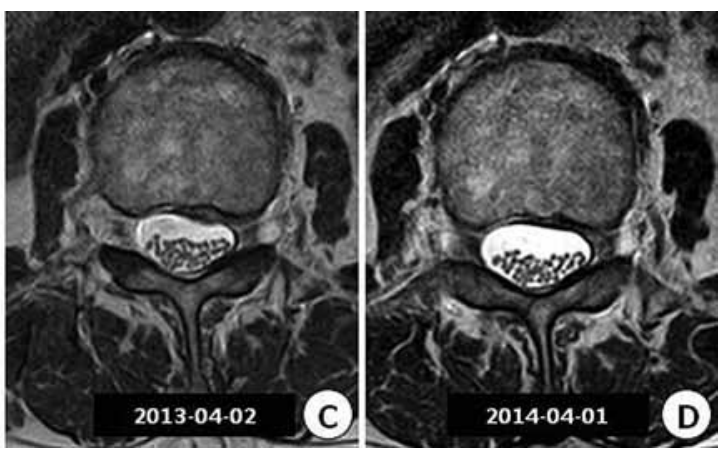

Fig. 6. A 69-year-old woman. T2-weighted axial views at the infrapedicular level of the L2 vertebral body with complete resorption of a left subarticular to foraminal disc protrusion at the L2-3 disc level. 
shrinkage, and the third is an inflammatory reaction and neovascularization resulting in gradual resorption of the cartilaginous tissue through enzymatic degradation and phagocytosis (20). Recently, Chiu et al (21) reported in their systemic review that predictive factors for spontaneous regression of LDH were extruded and sequestrated types of herniation, migrated disc, transligamentous herniation, herniation with contrast enhancement, and high MRI T2 signal intensity of the herniated disc. They also reported that the rate of spontaneous regression was found to be $96 \%$ for disc sequestration, $70 \%$ for disc extrusion, $41 \%$ for disc protrusion, and $13 \%$ for disc bulging. In our study, the rate of spontaneous resorption was $80 \%$ (16/20) for disc extrusion and $100 \%$ (8/8) for disc protrusion. Although only a small number of patients with massive lumbar disc protrusion were included in our study, the resorption rate was different from that of Chiu's report. As 7 of 8 patients who had a migrated disc showed a reduction in the size of the disc in our study, we also suggest that a migrated disc is a strong predictive factor for spontaneous regression of $\mathrm{LDH}$.

Lama et al (22) suggested that hyaline cartilage fragments existing within herniated disc tissue show little swelling or proteoglycan loss, and may be slow to resorb, increasing the risk of persisting sciatica. The clinical consequences from the loss of endplate barrier function are inflammatory endplate changes ("Modic classification") and bacterial infections within the disc (23). Ding et al (24) reported that Modic changes of lumbar endplates are strongly associated with poor resorption of LDH after conservative treatment. They reported that patients with Modic changes exhibit significantly increased cartilage content and decreased neovascularization and macrophage infiltration in herniated disc tissue, all of which are known to impair spontaneous resorption of herniated tissues. Modic changes of lumbar endplates were observed in $21.4 \%$ (6/28) of patients in our study. Two patients with Modic type I changes and 2 patients with type II changes were observed in the resorption group (4/24), and 2 patients with type II changes were observed in the non-resorption group (2/4). The incidence of Modic changes was not very high in the resorption group, which is consistent with the findings of previous studies.

Autio et al (25) reported that the age category 41 - 50 years was associated with a higher resorption rate. Herniated discs in older patients have been speculated to be harder, more fibrotic, and drier than those in younger patients. Less nucleus pulposus tissue and more annulus fibrosis and cartilaginous endplate material in herniated discs have been suggested to inhibit neovascularization. On the other hand, Seo et al (19) reported that the extent of LDH resorption was not correlated with age and the volumetric increment was higher in older than younger patients. In our study, not only did all 11 patients aged $41-50$ years show a reduction in the size of the disc, but also all 6 patients over 60 years also showed a reduction of the disc, and 3 of them showed complete resorption. We think that the association between disc resorption and age is not conclusive and further studies are needed to assess the relevance.

The most common cause of CES is disc disease (26). However, there is no consistent correlation between the size of the protruded or extruded disc on MRI and the degree of patient symptomatology (27). In some cases, significant compression produces few symptoms. In other cases, modest compression may produce CES. It appears that the cauda equina may vary in its ability to withstand compression (28). CES occurs in approximately 1 to $2 \%$ of cases of $\operatorname{LDH}(29,30)$, but the fear of CES causes more patients with massive LDH to undergo decompression surgery. Although our study showed that patients experienced marked symptomatic improvements with disc resorption, the correlation between clinical improvement and the extent of disc resolution is still controversial. This discrepancy is explained by proposing that compression is not the only explanation for the symptoms and that they are due as well to the release of inflammatory chemicals from the diseased disc and the composition of the herniated disc itself $(18,19)$.

In the clinical evolution of LDH in patients undergoing non-surgical treatment, it has been reported that fluoroscopically directed epidural injections provide long-term improvement in back and lower extremity pain for patients with lumbar discogenic pain (31). The effectiveness (at least $>50 \%$ reduction in pain between pre-injection and post-injection pain scores) of lumbar interlaminar epidural injections with or without steroids for the treatment of disc herniation varies from $67-85 \%$ long-term (32). Manchikanti et al (33) also demonstrated a slight superiority of steroids compared with local anesthetic alone in a randomized, doubleblind, active controlled trial with a 2-year follow-up. The long-term success for TFESI has been reported to range from $71-84 \%(34,35)$.

In our study, the mean VAS scores at 2 weeks after TFESI and at the second MRI were significantly decreased compared to the initial VAS scores. The relief of pain is 
thought to be due to local effects of steroid on nerve root edema and edema surrounding the disc material. Our results support that an inflammatory response as well as nerve root compression play an important role in the symptoms of massive LDH.

There are several limitations in this study. First, the data collection was retrospective in nature, and included patients who chose not to undergo surgery, introducing a potential bias in the population studied. Second, the timing of repeat imaging was not standardized or consistent, because not all patients in this study were examined by MRI at regular intervals. Finally, the study population consisted mainly of patients who did not show progressive neurologic deficits or prolonged intractable leg pain, although some met the criteria reported for surgical treatment reported.

\section{Conclusion}

In conclusion, our analysis showed an improvement in the symptoms of massive LDH and reduction in the size of the herniated disc through conservative treatment. Even in the patients whose disc herniation did not resolve radiologically, the symptoms had diminished to such an extent that surgery was not required. Although surgical treatment is faster and more complete in relieving symptoms, due to its invasiveness and complications there has been a growing interest in nonsurgical treatment for LDH. The majority of cases of massive LDH had resolved at variable points between 3 and 21 months. TFESI can provide effective pain relief in the interval for patients with massive LDH without severe neurologic deterioration.

\section{References}

1. Spangfort EV. The lumbar disc herniation. A computer-aided analysis of 2,504 operations. Acta Orthop Scand Suppl 1972; 142:1-95.

2. O'Laoire SA, Crockard HA, Thomas DG. Prognosis for sphincter recovery after operation for cauda equina compression owing to lumbar disc prolapse. $\mathrm{Br}$ Med J 1981; 282:1852-1854.

3. Gibson JN, Waddell G. Surgical interventions for lumbar disc prolapse: Updated Cochrane Review. Spine 2007; 32:1735-1747.

4. Matsubara Y, Kato F, Mimatsu K, Kajino G, Nakamura S, Nitta H. Serial changes on MRI in lumbar disc herniations treated conservatively. Neuroradiology 1995; 37:378-383.

5. Takada E, Takahashi M, Shimada K. Natural history of lumbar disc hernia with radicular leg pain: Spontaneous MRI changes of the herniated mass and correlation with clinical outcome. J Orthop Surg 2001; 9:1-7.

6. Fardon DF, Williams AL, Dohring EJ, Murtagh FR, Gabriel Rothman SL, Sze GK. Lumbar disc nomenclature: Version 2.0: Recommendations of the combined task forces of the North American Spine Society, the American Society of Spine Radiology and the American Society of Neuroradiology. Spine J 2014; 14:2525-2545.

7. Weber $\mathrm{H}$. Lumbar disc herniation. A controlled, prospective study with ten years of observation. Spine 1983; 8:131-140.

8. Guinto FC Jr, Hashim $\mathrm{H}$ and Stumer M. CT demonstration of disk regression after conservative therapy. Am J Neuroradiol 1984; 5:632-633.

9. Teplick JG, Haskin ME. Spontaneous regression of herniated nucleus pulposus. Am J Roentgenol 1985; 145:371-375.

10. Saal JA, Saal JS, Herzog RJ. The natural history of lumbar intervertebral disc extrusions treated nonoperatively. Spine 1990; 15:683-686.

11. Bush K, Cowan N, Katz DE, Gishen P. The natural history of sciatica associated with disc pathology: A prospective study with clinical and independent radiological follow-up. Spine 1992; 17:1205-1212.

12. Bozzao A, Gallucci M, Masciocchi C, Aprile I, Barile A, Passariello R. Lumbar disc herniation: MR imaging assessment of natural history in patients treated without surgery. Radiology 1992; 185:135-141.

13. Weber $\mathrm{H}$, Holme I, Amlie E. The natura course of acute sciatica with nerve root symptoms in a double-blind placebocontrolled trial evaluating the effect of piroxicam. Spine 1993; 18:1433-1438.

14. Komori H, Shinomiya K, Nakai O, Yamaura I, Takeda S, Furuya K. The natural history of herniated nucleus pulposus with radiculopathy. Spine 1996; 21:225-229.
15. Jensen TS, Albert HB, Soerensen JS, Manniche C, Leboeuf-Yde C. Natural course of disc morphology in patients with sciatica: An MRI study using a standardized qualitative classification system. Spine 2006; 31:1605-1613.

16. Awad J, Moskovich R. Lumbar disc herniations: Surgical versus nonsurgical treatment. Clin Orthop Relat Res 2006; 443:183-197.

17. Cribb GL, Jaffray DC, Cassar-Pullicino VN. Observations on the natural history of massive lumbar disc herniation.] Bone Joint Surg Br 2007; 89:782-784.

18. Benson RT, Tavares SP, Robertson SC, Sharp R, Marshall RW. Conservatively treated massive prolapsed discs: $A$ 7-year follow-up. Ann R Coll Surg Engl 2010; 92:147-153.

19. Seo JY, Roh YH, Kim YH, Ha KY. Threedimensional analysis of volumetric changes in herniated discs of the lumbar spine: Does spontaneous resorption of herniated discs always occur?. Eur Spine] 2014 Sep 25. [Epub ahead of print].

20. Teplick JG, Haskin ME. Spontaneous regression of herniated nucleus pulposus. Am J Roentgenol 1985; 145:371-375.

21. Chiu CC, Chuang TY, Chang KH, Wu $\mathrm{CH}$, Lin PW, Hsu WY. The probability of spontaneous regression of lumbar herniated disc: A systematic review. Clin $\mathrm{Re}$ habil 2015; 29:184-195. 
22. Lama P, Zehra U, Balkovec C, Claireaux HA, Flower L, Harding IJ, Dolan P, Adams MA. Significance of cartilage endplate within herniated disc tissue. Eur Spine J 2014; 23:1869-1877.

23. Albert HB, Lambert P, Rollason J, Sorensen JS, Worthington T, Pedersen MB, Nørgaard HS, Vernallis A, Busch F, Manniche C, Elliott T. Does nuclear tissue infected with bacteria following disc herniations lead to Modic changes in the adjacent vertebrae? Eur Spine J 2013; 22:690-696.

24. Ding L, Teng X, Fan S, Zhao F. The association between Modic changes of lumbar endplates and spontaneous resorption of herniated intervertebral discs. Cell Biochem Biophys 2015; 71:1357-1363.

25. Autio RA, Karppinen J, Niinimäki J, Ojala R, Kurunlahti M, Haapea M, Vanharanta $\mathrm{H}$, Tervonen O. Determinants of spontaneous resorption of intervertebral disc herniations. Spine 2006; 31:1247-1252.

26. Spector LR, Madigan L, Rhyne A, Darden $B$ 2nd, Kim D. Cauda equina syndrome.
J Am Acad Orthop Surg 2008; 16:471-479.

27. Schoenfeld AJ, Bader JO. Cauda equina syndrome: An analysis of incidence rates and risk factors among a closed North American military population. Clin Neurol Neurosurg 2012; 114:947-950.

28. Venkatesan $M$, Uzoigwe CE, Perianayagam G, Braybrooke JR, Newey $M L$. Is cauda equina syndrome linked with obesity? J Bone Joint Surg Br 2012; 94:1551-1556.

29. Kostuik JP, Harrington I, Alexander D, Rand W, Evans D. Cauda equina syndrome and lumbar disc herniation. J Bone Joint Surg 1986; 68:386-391.

30. Henriques T, Olerud C, Petre' $n$ Mallmin M, Ahl T. Cauda equine syndrome as a postoperative complication in five patients operated for lumbar disc herniation. Spine 2001; 26:293-297.

31. Manchikanti L, Staats PS, Nampiaparampil DE, Hirsch JA. What is the role of epidural injections in the treatment of lumbar discogenic pain: A systematic review of comparative analysis with fusion. Korean J Pain 2015; 28:75-87.

32. Manchikanti L, Singh V, Cash KA, Pampati V, Falco FJ. The role of fluoroscopic interlaminar epidural injections in managing chronic pain of lumbar disc herniation or radiculitis: A randomized, double-blind trial. Pain Pract 2013; 13:547-558.

33. Manchikanti L, Singh V, Cash KA, Pampati V, Falco FJ. A randomized, doubleblind, active-control trial of the effectiveness of lumbar interlaminar epidural injections in disc herniation. Pain Physician 2014; 17:E61-E74.

34. Lutz GE, Vad VB, Wisneski RJ. Fluoroscopic transforaminal lumbar epidural steroids: An outcome study. Arch Phys Med Rehabil 1998; 79:1362-1366.

35. Vad VB, Bhat AL, Lutz GE, Cammisa F. Transforaminal epidural steroid injections in lumbosacral radiculopathy: A prospective randomized study. Spine 2002; 27:11-16. 